\title{
Enlightening Resistive Production Case Study: Oil, Gas and Petrochemicals
}

Safar Shasfand

\author{
Member of the maintenance steering committee of the Oil Ministry of Iran \\ PhD Student of Systems and Productivity in Science and Technology University, Iran
}

\section{Seyed Mohammed Seyed Husseini}

Supervisor: Professor Seyed Mohammed Seyed Husseini, IUST, Iran

Kamran Shahanghi

Advisor: Dr. Kamran Shahanghi, IUST, Iran

\section{Doi:10.5901/mjss.2016.v7n4s2p82}

\begin{abstract}
This is enlightening resistive production with the case study of oil, gas, refining and petrochemical aiming to representing the required production of base activities of oil. As Supreme Leader of the Revolution and senior officials of country have introduced the resistive economy and have considered main role for oil ministry in this economy, this ministry requires resistive economy to achieve the objectives of the sixth plan and twenty-year document of the country. The considered resistive economy is condition-oriented economy evoking the lean production. Four pillars of the resistive maintenance and production include personnel, equipment, knowledge and management. The resistive production approach is not only future-oriented approach but also it is process-oriented seeking to endogeneity and extraversion and minimizing the foreign dependence. Resistive Production and maintenance help in achieving to strategic objectives.
\end{abstract}

Keywords: Resistive maintenance and production, resistive economy, endogeneity, extroversion, process approach, conditionsbased production, excellence model, availability, reliability and roadmap

\section{Introduction}

This paper aims to provide an understanding of resistive economy and examine oil and gas, refining, petrochemical conditions. Then, it investigates the features of production and maintenance in the case studies. In this paper, the views of industry experts, professors and researchers' observations were used.

\subsection{An understanding of resistive economy}

Resistive economy is an Islamic-Iranian model[1] aiming to continues its development and growth (development model) and become international model in the unstable, changing, indecisive and uncertain conditions of the current world by relying on its internal capacity (endogeneity) and interact with world powers (extraversion) against pressure, threats, and environmental and external conflicts as well as internal weaknesses (resistive). By designing and implementing indigenous and scientific process of resistive economy, we can control and reduce the effects of pressure and inhibitory factors (to minimize the inhibitory factors) and increase the driving factors (to maximize the driving factors). Dynamism, flexibility, agility, accountability, future-oriented, and stability are features of the resistive economy that each country can use the advantages of these features depending on level of its capability, potential, knowledge and action with endogeneity and extroversion approach.

According to researcher of this study all developed countries of the world have resistive economy, while their resistive coefficient, the level of social justice, profit ratios, and ownership of three elements of endogeneity, extroversion and external consumption are different. Existing conditions (interactions, interferences, defenses, offenses, impressions, thoughts, prosperities) between the countries cause resistive economy created by conditions. Therefore, this kind of economy is condition based, that is, it is created under some conditions. 
(Resistive Economy $\approx$ Condition based Economy)

Resistive economy is an urgent and strategy for survival and development of Islamic Republic of Iran due to governing and independence, Islam-seeking, and strategic position and the conditions and factors causing serious disorder and opposition mainly with foreign countries. National consensus, good governance, coordination between the three executive, legislative and judicial branches paves the way for resistive economy. There is not still strong evidence that suggests the culture and discourse of resistive economy have been institutionalized in our country. Based on SWOT analysis, resistive economy is facing with challenges listed in the table below. Strengths (S), weaknesses (W) are internal factors and opportunities (O), and threats $(\mathrm{T})$ are external factors.

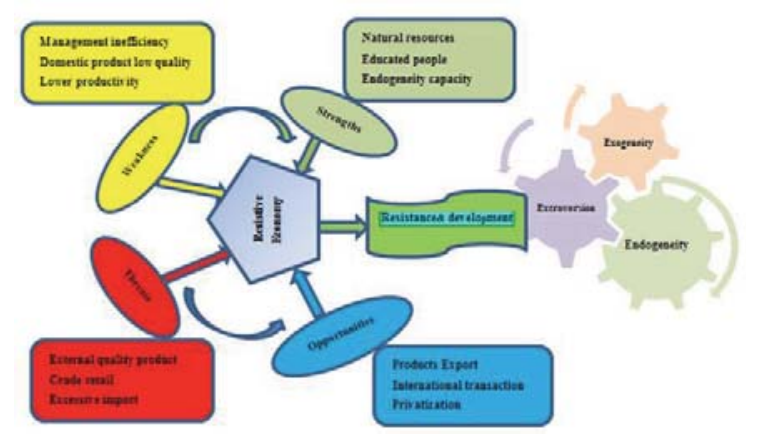

Figure 1. Resistive economy system

Resistive economy gives optimal response to needs and expectations against internal and external pressures.

\section{Table1. SWOT matrix}

\begin{tabular}{|c|c|}
\hline 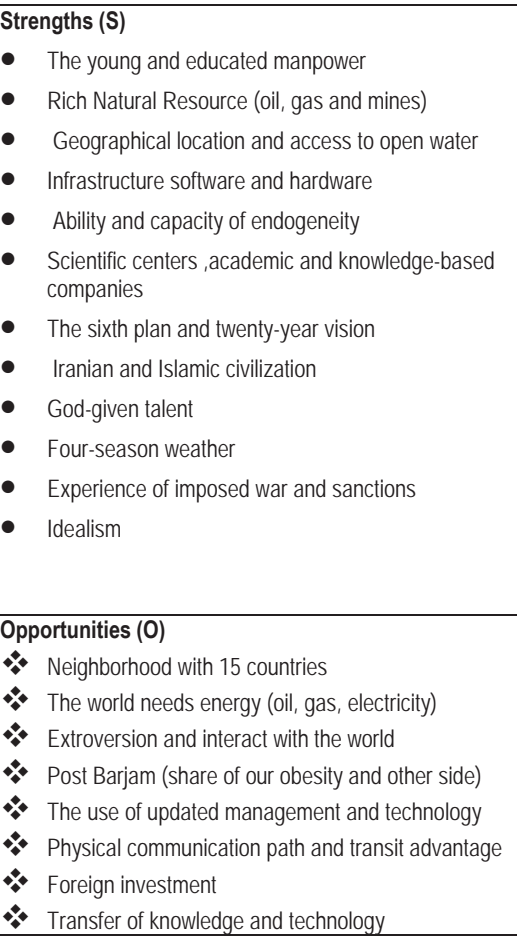 & $\begin{array}{l}\text { Weaknesses (W) } \\
\text { - Inefficient state-run economy, semi-state economy, and poor private sector } \\
\text { - Consumerism, excessive imports and interest in foreign production } \\
\text { - Low quality and desirability of domestic production } \\
\text { - Politicization, lack of meritocracy and lack of coordination between the three } \\
\text { branches } \\
\text { - lack of growth and development in scientific management and lack of } \\
\text { strategic managers } \\
\text { - High I and wandering liquidity, corruption, speculation } \\
\text { - Budget dependence on crude oil sales } \\
\text { - Chronic inflation, budget deficit, unemployment and low productivity } \\
\text { - Deficiency in the financial, banking, monetary and custom system of the } \\
\text { - Nauntry } \\
\text { - Low road safety and air pollution. } \\
\text { - Inhibitory bureaucracy and complicated, non-transparent, uninterpretable } \\
\text { regulation and implementation of them based individual interests } \\
\text { Threats (T) } \\
\text { Sanctions, conflicts and wars in the Middle East } \\
\text { Political and religious conflicts in the region }\end{array}$ \\
\hline
\end{tabular}


Table 2. Target function variables of resistive economy

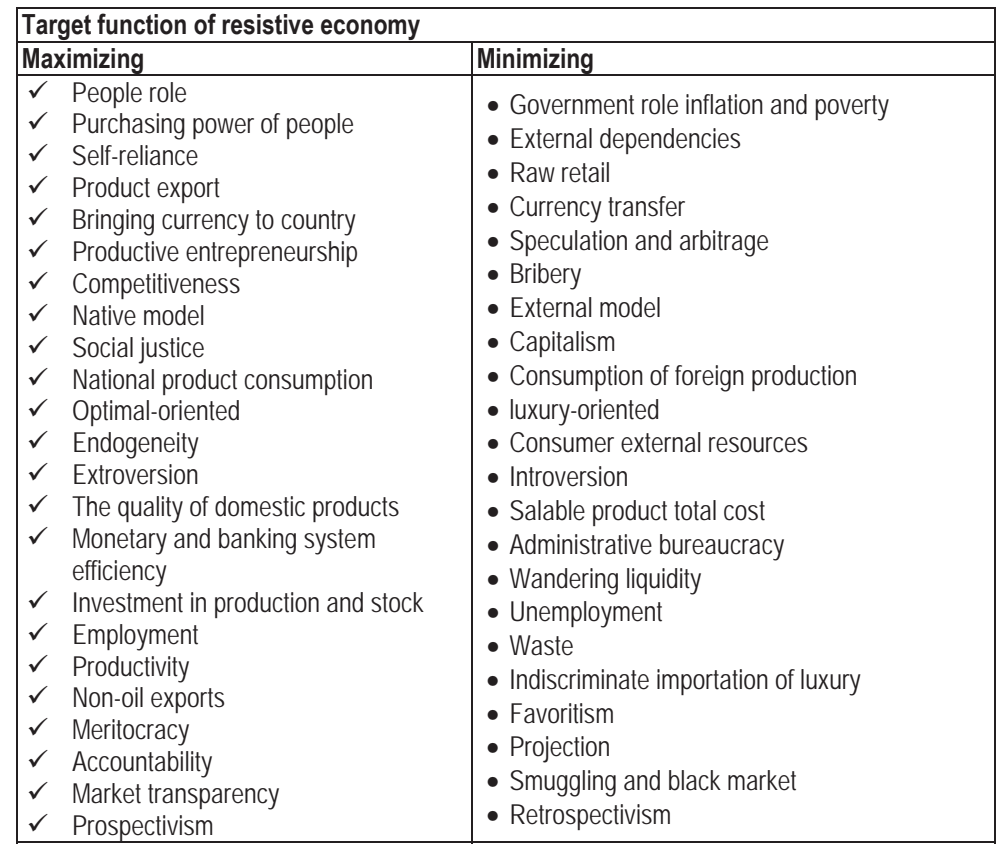

\subsection{Oil, gas and petrochemical industries at a glance}

Achilles heel of Iran's economic is dependence on crude oil sales and determination of its price by external factors, for example, in the confrontation space and sanctions, the price of oil is $\$ 130$, while it is $\$ 40$ in the interaction space. The increased government costs and reduced income sources can cripple any country. The economy that is dependent on crude oil sales cannot be sustainable economy. The high pressure resulting from dynamic crude oil forfeits the endogeneity and the system, and in the most optimistic situation, it can survive with cancer pain and displays superficial resistance. However, ignore the development, being model, internal resistance leading to bankruptcy, submission and dependency. In the current circumstances and in the short term, the is no way just selling crude for living, while along with it, according to sixth development plan, we must minimize the crude oil sale and maximize the conversion of crude oil to oil and petroleum products. The share of products export must be maximized in addition to meeting the current and future needs. By doing this, we can reduce dependency to crude oil and increase the brining the currency to our country, improve the endogeneity by developing the export value-added chain (Oil, gas and petrochemical), and this is one of the ways to strengthen the economy. Generally, oil has two faces. On one hand, according to Terry Lynn, it can acts as poison [2] for managers making decision leading to misery, laziness, dependency and ignorance of a nation. On the other hand, as god given gift, it can lead to happiness, agility, independence, and guidance of a nation. It depends on this issue that how it is used. Oil well can give crude oil, instead, it can fall human that well. Currently, our need to extract Joseph is more that crude oil. In the sixth development plan of the country, about 203 milliard dollars seems to be required for oil projects and to reach the level of resistive economy [3]. It seems that the government at the current conditions can supply about 20 to 40 milliard dollars of it from its income sources during the plan. To supply its remaining, five ways come to mind.

1. To sell oil through stock exchange to maximize its price

2. Increasing the crude oil caused by external factors

3. Absorbing domestic wandering investments

4. Absorbing maximized external investment and monitoring the minimized external dependency

5. To manage costs, resources and expenditures 
Table 3. The objective function of Oil, Gas and Petrochemical

\begin{tabular}{|l|l|}
\hline \multicolumn{2}{|c|}{ The objective functions of Oil, Gas and Petrochemical } \\
\hline Maximizing & Minimizing \\
\hline Export of oil, gas and petrochemical products & Crude oil exports \\
\hline Capacity and quality of production (utility) & Cost and environmental and safety events \\
\hline God given gift and great value & Evil curse and falling into the trap of abundance \\
\hline Resource efficiency and management of energy consumption & Waste of resources and waste of energy \\
\hline $\begin{array}{l}\text { The role of the real private sector in downstream industries and } \\
\text { producing products }\end{array}$ & $\begin{array}{l}\text { Tenure of public sector in production of oil, gas } \\
\text { and petrochemical }\end{array}$ \\
\hline Attracting domestic and foreign investments & Investment risk and foreign dependence \\
\hline Meritocracy in the appointment of strategic managers & Politicization, favoritism, and narrow-mindedness \\
\hline
\end{tabular}

\subsection{Resistance operation (production, logistics, maintenance) at a glance}

Production in the resistive economy is the production producing a product relying on domestic resources and capacities with maximum quality $(6 \delta)$, flawless and quick (lean) and the minimum cost (Min COGS) satisfying the needs and demands of customer and making them loyal. Efficient maintenance supports lean production [4]. It can be said that resistive maintenance is formed within the lean production space. In other words, the maintenance supporting the lean production is called as resistive maintenance. The lean production founded on domestic potential at maximum level represents the resistive economy. On the other hand, logistics required for resistive operation in the post-sanction period is a challenge being studied [5].

Table 4. The variables of objective function of Oil, Gas and Petrochemical

\begin{tabular}{|l|l|}
\hline \multicolumn{2}{|l|}{ The objective function of Oil, Gas and Petrochemical } \\
\hline Maximizing & Minimizing \\
\hline Capacity, quality and product diversity & Salable product cost \\
\hline Valuable oil related products (petroleum and petrochemical) & Low-value products \\
\hline Leanness and agility & Energy loss \\
\hline The centrality of internal resources & Reliance on external resources \\
\hline Market share, competitiveness and exports & Bribery, monopoly, foreign imports \\
\hline Absorbing domestic and foreign investment & Government facilities \\
\hline Safety, health and environmental protection & Safety events, environmental degradation \\
\hline
\end{tabular}

With available capital and sixth plan, it is going to have production capacity at investments of 600 milliard dollars in the oil industry. Such production will certainly need to support and protection of the production factors. In the lean production space, we need timely supply chain when and effective maintenance based on conditions.

In the sixth plan, oil ministry seeks to increase the capacity of crude oil and gas condensate, to increase the capacity of rich gas production, to increase uptake of shared oil and gas resources, value chain completion and development of refining industry and petrochemical industry.[6]

Table 5. Sixth plan of oil industry in the resistive economy

\begin{tabular}{|l|l|l|c|c|c|}
\hline & Objective & Unit & $\mathbf{2 0 1 5}$ & $\mathbf{2 0 2 0}$ & Annual growth (\%) \\
\hline 1 & Natural gas exports & Million cubic meters per day & 28 & 131 & 36.2 \\
\hline 2 & Valuable products export & Million liters per day & 12.9 & 132 & 59.2 \\
\hline 3 & Reducing low-value products & Million liters per day & 36.1 & 21.7 & $9.7-$ \\
\hline 4 & Petrochemical exports & Million tons per year & 14.1 & 41.2 & 23.9 \\
\hline 5 & Increasing crude oil production capacity & Thousand barrels per day & 3388 & 5292 & 9.3 \\
\hline 6 & Increasing gas production capacity & Million cubic meters per day & 756 & 1254 & 10.7 \\
\hline 7 & The development of refining industry & Thousand barrels per day & 1810 & 2700 & 8.3 \\
\hline 8 & The development of the petrochemical industry & Million tons per year & 27.1 & 64.2 & 18.8 \\
\hline 9 & Value sales of petrochemical products & Million dollars per year & 21973 & 51460 & 18.6 \\
\hline
\end{tabular}




\section{Resistive Maintenance}

As resistive economy, resistive maintenance is based on the conditions [7]. Four key elements of resistive maintenance are personnel, equipment, knowledge, and management. It is affected by internal and external factors and affects them (mutual effect). Using Figure below, we can measure the rate of resistive endogeneity and extraversion at all times. For these variables, we must design a model that has driving and implementable approaches, valid and effective indicators (KPI) that can be evaluated and measured so that the distance between the measured indicators and the target indicators can be analyzed immediately. This model should be changed over time to make it updated. Such model should be nativescientific brand of country with an approach maximizing endogeneity and extraversion and minimizing exogeneity.

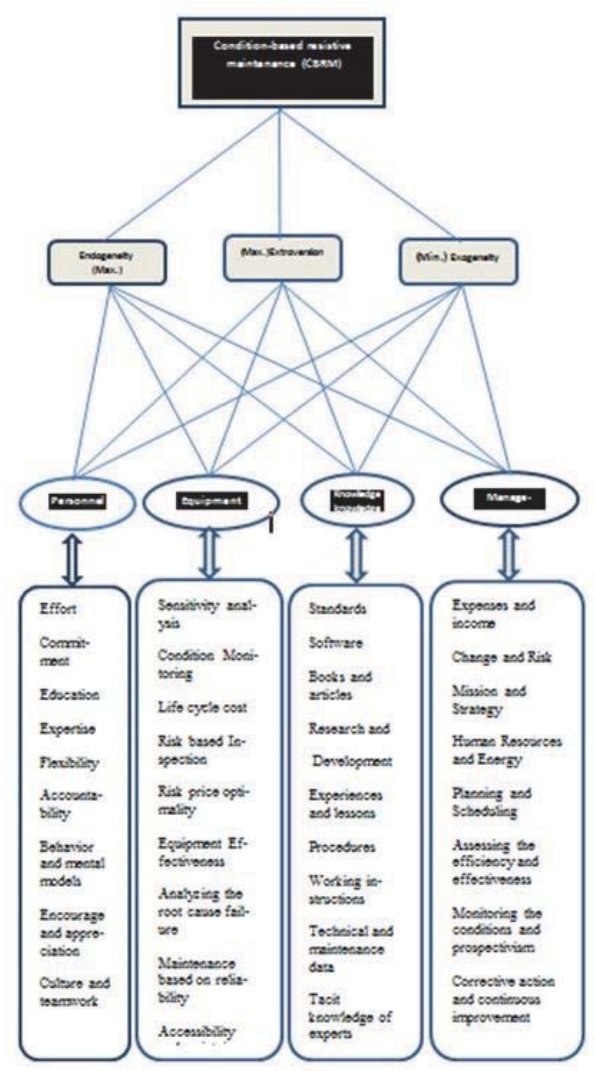

Figure 2. Resistive maintenance variables

\section{Excellence Roadmap of Oil}

The oil maintenance excellence roadmap proposed by Directorate General of Oil Maintenance is as follows. [8] 


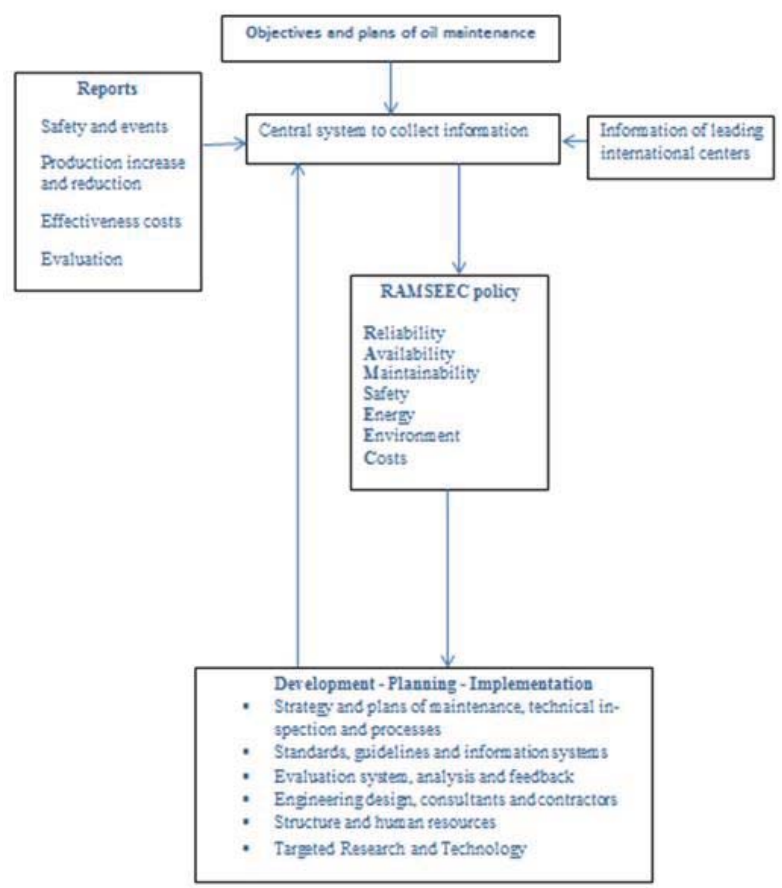

Figure 3. Excellence roadmap of oil maintenance

\section{Management of the Petrochemical Production and Maintenance}

In the Table 6, the causes of reduced production for four consecutive years in Iran's petrochemical industry [9] have been shown. Almost $40 \%$ is due to the occurrence operational and maintenance problems. In other words, we have experienced about 5 million reduction in the production led to an increase in the total cost of the products, reduction in the profitability. It has also caused weakness in the competitive market. For competitive, agile, and lean production, we must find the basic causes of the reduced production. The maintenance defects and problems show that maintenance authorities have reduced these problems relatively. The obtained results showed that despite sanctions lower percentage of the production is due to shortage of chemicals and spare parts. The other point is that by initiating Asaluye gaseous phase the problem of feed shortage has been reduced in some part. As a result, maintenance and procedural problems increase. It is required that make necessary measures to increase the operational and maintenance capability.

Table 6. The causes of reduced production

\begin{tabular}{|l|c|c|c|c|}
\hline Production loss & $\mathbf{2 0 1 1}$ & $\mathbf{2 0 1 2}$ & $\mathbf{2 0 1 3}$ & $\mathbf{2 0 1 4}$ \\
\hline Lack of Feed \% & 36.5 & 33.4 & 48.2 & 45.5 \\
\hline Maintenance Problems \% & 26.1 & 19.2 & 17.2 & 20.2 \\
\hline Production problems \% & 21.8 & 15.8 & 10.8 & 18.5 \\
\hline Sales Problems \% & 11.2 & 24.3 & 16.8 & 10.4 \\
\hline Others \% & 4.4 & 7.3 & 7 & 5.4 \\
\hline
\end{tabular}

Sometimes, the production unit has been in the operation, but for various reasons it has worked with low capacity. On average, 75 percent of complexes have been salable and remaining products is among the producing units. On average, decrease in the production of petrochemical complexes has been recorded as process factors and occurrence of maintenance problems. By calculation of accessibility of manufacturing units, it was determined that over the 8 years, the 
manufacturing units have been active in $91 \%$ of their expected time, and the rate of their products has been with $73 \%$ of the capacity. Therefore, we have lost almost 65 million tons production during the eight years. By calculation of the share related to maintenance, we have lost the possibility of selling 26 million tons due to lack of using accessibility of manufacturing unit that by assuming 600 dollars to selling each tons petrochemical product, we have lost 600 million dollars annually. In addition, we have lost 39 million tons of production during the 8 years that we have lost 680 million tons in this regard [10].

Table 7. Actual production to capacity process

\begin{tabular}{|l|c|c|c|c|c|c|c|c|}
\hline Year & $\mathbf{2 0 0 8}$ & $\mathbf{2 0 0 9}$ & $\mathbf{2 0 1 0}$ & $\mathbf{2 0 1 1}$ & $\mathbf{2 0 1 2}$ & $\mathbf{2 0 1 3}$ & $\mathbf{2 0 1 4}$ & $\mathbf{2 0 1 5}$ \\
\hline Actual production (million tons) & 27.0 & 31.4 & 40.5 & 42.7 & 41.0 & 40.5 & 44.5 & 36.5 \\
\hline The actual production to Capacity (\%) & 68 & 73 & 79 & 79 & 74 & 71 & 78 & 74 \\
\hline
\end{tabular}

Quality management factors including TQM, TPM, RBI, RCA, and QC require maintenance and production structure[11]. With integrating the systems and updating the techniques in the petrochemical industries, companies try to achieve results such as quality, safety, productivity, reliability, and reduced costs. Experts believe that using these concepts by maintenance system can lead to increased competitiveness in the petrochemical industries.

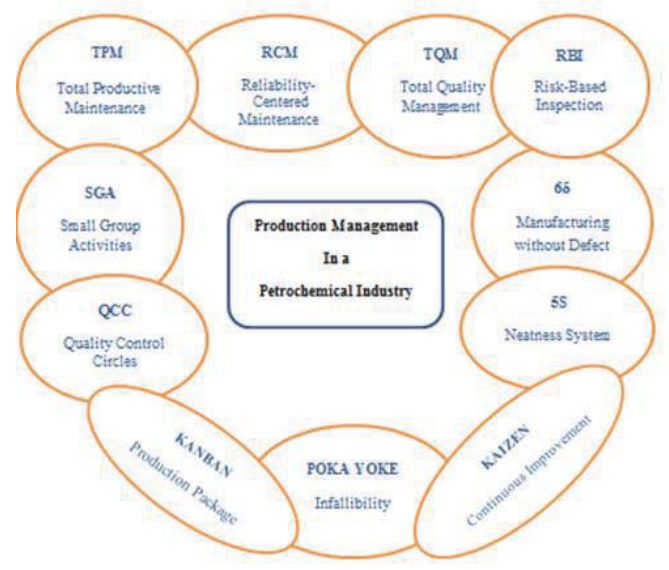

Figure 4. Circles of Operation Management for the petrochemical industry

Using top experiences includes 12 areas shown in Table 8 (Sharma at el. 2008) (12)

Table 8. Top experience elements of maintenance

\begin{tabular}{|ll|ll|}
\hline $1-$ & Leadership and Policy making & $7-$ & Planning and Scheduling \\
2- & Organizational Structure & $8-$ & Work flow \\
3- & Inventory control & $9-$ & Financial Control \\
4- & CMMS & 10- & Operational Partnership \\
5- & Preventive maintenance PM & 11- & Organizing and Development \\
6- & Predictive maintenance & $12-$ & Continuous Improvement \\
\hline
\end{tabular}

\section{The Production Process and Maintenance Process}

The input and output process of the production and maintenance resistive model is according to Figure 5. Inputs are obtained based on the assessment and SWOT analysis and outputs are defined as measurable parameters. Resistive production and maintenance is condition-based process. In the resistive production and maintenance, parameters affect each other [13]. 


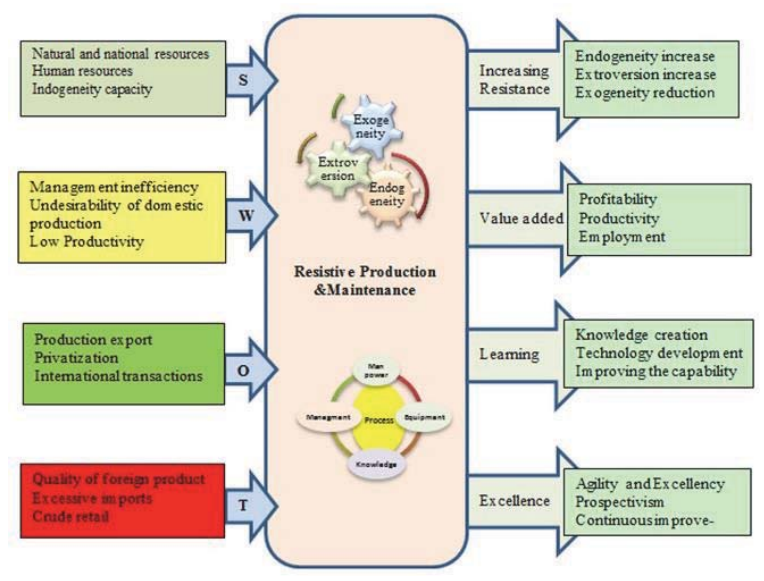

Figure 5. The process of resistive production and maintenance

\section{Conclusion}

It can be said that resistive production and maintenance can be vital and urgent to achieve some objectives listed in Table 9. Using excellence model of production and maintenance, we can increase the production capacity by 10-15\% (5 to 8 million tons in the petrochemical industry).

Table 9. Some examples of resistive production objectives

\begin{tabular}{|c|c|}
\hline $\begin{array}{ll}\text { 1- } & \text { Maximizing equipment reliability } \\
\text { 2- } & \text { Maximizing the production } \\
\text { 3- } & \text { Minimizing production cost }\end{array}$ & $\begin{array}{ll}\text { 4- } & \text { Minimizing risk } \\
\text { 5- } & \text { Removing the defect of product } \\
\text { 6- } & \text { Prevention from failure }\end{array}$ \\
\hline
\end{tabular}

In addition to the above objectives, the resistive model must have process-based approach, specified execution methodology, and specified responsibilities, authorities, and communications, capability to change based on conditions, flexibility to change in conditions. In contrast, it must be resistant against preventive factors. One of the challenges in the resistive production and maintenance is its modeling that can be measurable and assessable. The researcher of this paper tries to develop a measurable model for resistive production and maintenance.

\section{References}

Khamenei A, (2014), Resistive Economy, www.khamenei.ir

Terry Lynn Karl,(209) "The mystery of abundance", translation by Jafar Kheirkhah, Ney publications, Iran 2009

Planning Department of the Ministry of Oil, (2015), www.mop.ir

Seyed Hosseini, SM, "Introduction to the inclusive maintenance ..." Tehran 2011

Kazemi, H. Shahanghi, K, Syed Hosseini, SM, (2015) "Designing a model for resistive operations. PhD thesis, Department of Industrial Science and Technology, fall 2015

Department of Research and Technology / Engineering Oil Ministry, Reported in December 2015

Shahanghi, K, "the class pamphlet ", University of Science and Technology, November 2015

Asle Arabi, AR, Presented at a meeting of the National Petrochemical Company dated 2015.2.7

Baghbani, S, Twenty-sixth meeting of petrochemical managers, Mashhad, November 2015

Baghbani, S, Ninth meeting of petrochemical managers, Mahshahr, December 2015

Prasanna N.K.K, Desai T.N., (2011) "Advanced Quality Management philosophies and Techniques-Applied to Maintenance Management in a Petrochemical Industry ", JERS / Vol.2/2011, 10-18

Ravi kumar G, kapil M. (2013) "maintenance: from total production maintenance to world class Maintenance "IJSRR 2. 2013, 1-23

Shasfand, S, The twenty-sixth meeting of petrochemical oil managers, Mashhad, November 2015 